\title{
"Design" Racional de Fármacos
}

\author{
PAULINA MATA*
}

As técnicas de "design" racional começam a ter um papel importante na descoberta de novos fármacos. Esta é actualmente uma área investigação muito activa, mas está ainda a dar os seus primeiros passos e, embora os avancos atingidos sejam espectaculares, há ainda um longo caminho a percorrer. De facto, o objectivo final, "design" de ligandos com alta afinidade a partir de informacões estruturais tridimensionais, ainda só pode ser parcialmente atingido devido à compreensão limitada das interacções não ligantes e efeitos de solvatação no reconhecimento molecular.

Neste artigo far-se-á uma breve exposicão das diversas fases do "design" racional de fármacos, problemas associados e técnicas desenvolvidas e discutir-se-ão as potencialidades deste método e da sua associação com a química combinatorial.

\section{INTRODUÇÃO}

Ocasionalmente a descoberta de um novo fármaco é fruto do acaso, mas em geral resulta de um processo longo e complexo(1,2) (Esquema 1). Envolve uma fase de triagem, em que um elevado números de compostos é submetido a uma variedade de ensaios biológicos, com o objectivo de identificar os que terão actividade numa determinada área (fármacos protótipo). Estes são depois optimizados, de forma a obter uma actividade satisfatória e simultâneamente menos efeitos secundários. Tal processo envolve a síntese $\mathrm{e}$ o teste de um número elevadíssimo de compostos, sendo por isso extremamente longo e caro. Tem ainda o inconveniente de não dar qualquer garantia de se encontrar o composto ideal. Por outro lado, tem a vantagem de não requerer muita informação acerca do mecanismo da doença em questão e da sua base molecular.

$\mathrm{O}$ "design" racional de fármacos é desde há muito um objectivo da indús- tria farmacêutica. Tem a vantagem de ser um processo mais rápido e com mais potencialidades para permitir identificar as moléculas mais adaptadas a cada situação e, portanto, reduzir dramaticamente os custos de desenvolvimento de um novo fármaco. Porém, só recentemente o desenvolvimento da ciência e da informática puderam tornar o "design" racional de fármacos um objectivo atingível. A crescente disponibilidade de modelos estruturais de proteínas de importância terapêutica (existem mais de 4000 estruturas tridimensionais de macromoléculas na Brookhaven Protein Data Bank, muitas das quais com interesse terapêutico(3)) e o conhecimento mais ou menos detalhado do mecanismo de algumas doenças a nível molecular originou recentemente um grande interesse da indústria farmacêutica e de investigadores nas universidades no "design" racional de fármacos(3-6).

É uma área de investigação extremamente complexa e que requer a colaboração de investigadores com competências muito diversas. Presentemente existe um grande número de aproximações à resolução deste problema e só o tempo e os resultados obtidos permitirão identificar os melhores. É, portanto, um ramo da ciência que está a dar os seus primeiros passos e, embora os avanços atingidos sejam espectaculares, há ainda um longo caminho a percorrer.

\section{Fases no processo de "design" racional de fármacos}

\section{Introdução}

Qualquer programa para "design" racional de fármacos tem que ter em conta os seguintes aspectos:

\section{1) Definição de restrições}

A interacção fármaco-proteina envolve reconhecimento molecular, portanto requer uma complementaridade de características geométricas e químicas. Assim, a primeira fase neste processo é precisamente a identificação das características geométricas e químicas das moléculas a gerar.

\section{2) Geração de estruturas}

Requer o desenvolvimento de um método que, com base nas restrições previamente identificadas, permita gerar possíveis soluções para o problema em estudo.

\section{3) Avaliação de estruturas:}

As soluções propostas devem ser razoáveis, o que requer uma avaliação considerando uma vasta gama de propriedades, de forma a apresentar ao utilizador apenas soluções interessantes.

4) Organização de resultados

Tipicamente estes programas produzem um elevado número de soluções. É, assim, necessário desenvolver técnicas para as agrupar e ordenar e pôr à disposição do utilizador ferramentes para analisar os conjuntos de soluções gerados.

Em todo este processo são fundamentais as técnicas de modelação molecular e os gráficos moleculares interactivos(7-9). Estas permitem visualizar e analisar toda a informação estrutural e soluções propostas e tornam possível uma compreensão rápida e intuitiva de uma vasta gama de dados estruturais, dinâmicos e químicos. Dado que o processo de "design" racional requer a participação de investigadores de áreas diferentes, muitas vezes a comunicação dos conceitos envolvidos tornar-se-ia extremamente difícil sem o recurso a estas técnicas.

Compostos Naturais ou Sintetizados

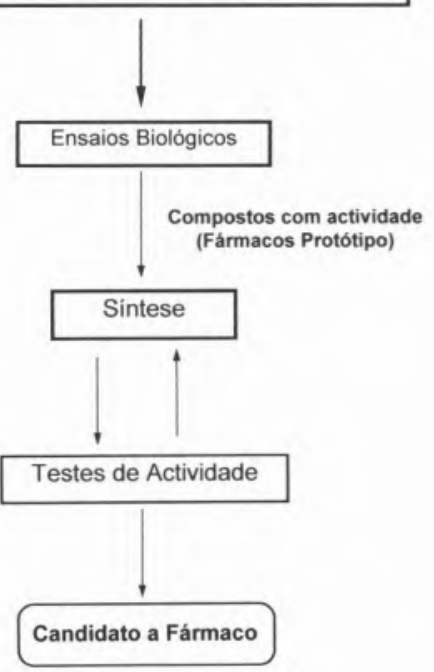

Esquema 1: Desenvolvimento de um Fármaco. Método Tradicional 


\section{Definição de Restrições}

A disponibilidade da estrutura de raio $\mathrm{X}$ da proteina envolvida num dado processo é em geral um bom ponto de partida. O processo de definição das restrições envolve normalmente a caracterização do sítio activo do receptor em termos geométricos e químicos e a posterior identificação de zonas potenciais de interacção (zonas da cavidade onde deverão existir átomos com determinadas características para estabelecer interacção com a proteina). Desta fase resulta, em geral, a determinação do volume da cavidade e superfície que o limita (fronteira Fig.1) e das zonas de interacção e conjunto de propriedades químicas a estas associadas.

Existem diversos programas para a caracterização do sítio activo do receptor que produzem os resultados em diferentes formatos que podem ser lidos pelos programas para geração de estruturas. Estes programas usam técnicas diferentes, para a identificação das zonas potenciais de interacção, que podem ser classificadas essencialmente em dois grupos:

1) Usando sondas moleculares que são colocadas em diferentes pontos da cavidade e cuja interacção com a proteina é calculada usando funções de energia.

O programas GRID(12) é um bom exemplo da utilização desta técnica. Os passos envolvidos são os seguintes:

- Definição de uma grelha 3D de pontos do sítio activo;

- Cálculo da energia de interacção entre uma sonda atómica e o receptor em cada ponto da grelha;

- Definição de zonas potenciais de interacção, com base nas interacções favoráveis identificadas;

- Exploração de diferentes tipos de interacção usando várias sondas (carbonilo, amina, hidroxilo...).

2) Analisando a estrutura da proteina para determinar o tipo de grupos funcionais na superfície da cavidade e usando regras empíricas para localizar zonas onde é de esperar que se verifique uma interacção forte (zonas potenciais de interacção). Exemplos destas regras são apresentadas na Fig.2 e
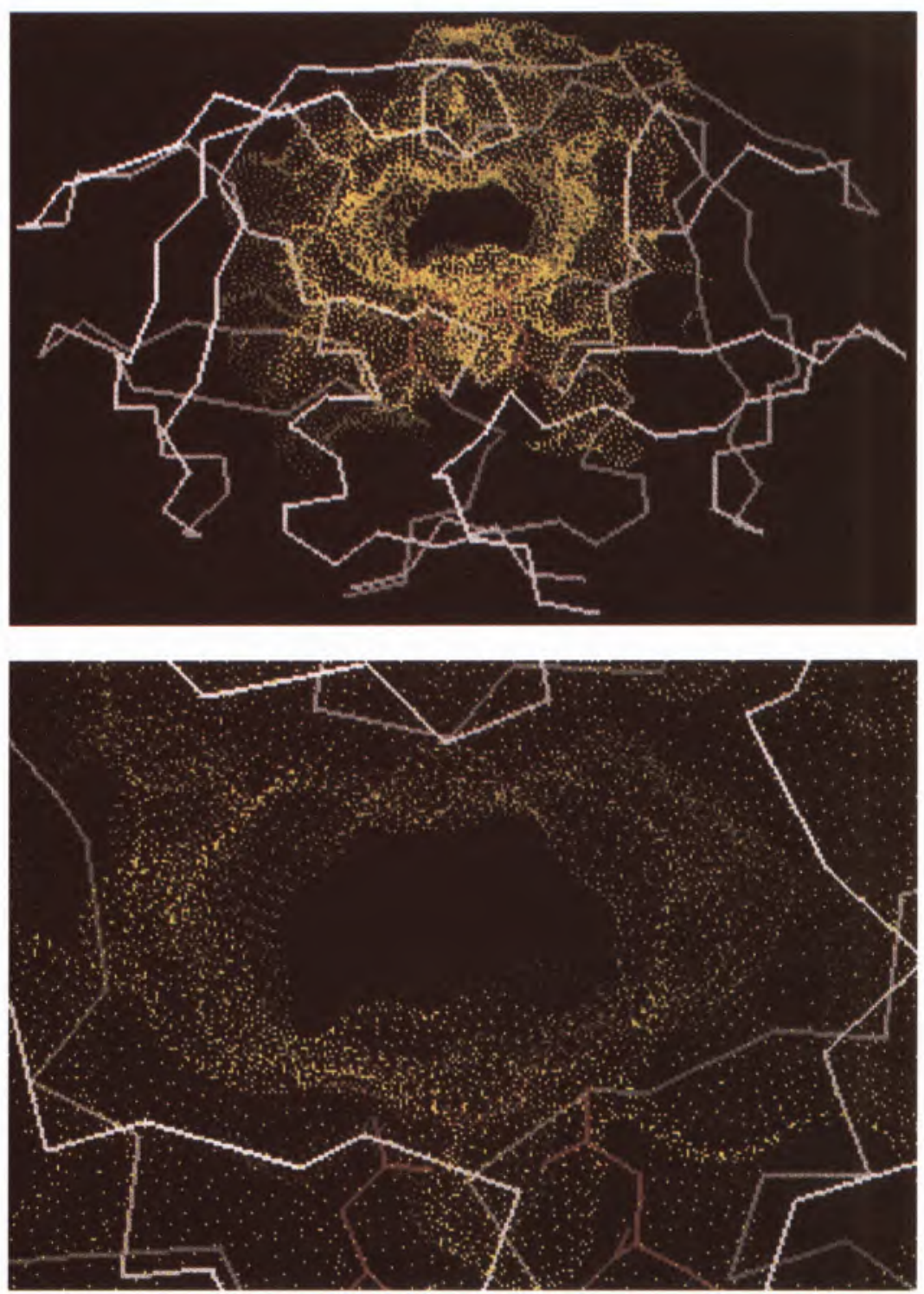

Fig. 1 - Superfície molecular do receptor HIV-1 protease, determinada pelo Molecular Surface Package (10) para ser usada pelo programa DOCK(11). Figura retirada da Ref.11.

na Fig.3. Frequentemente, quando existe informação estrutural sobre complexos da proteina com outros ligandos, o tipo de interacções existentes e a posição dos átomos dos ligandos podem também ser usados para localizar zonas potenciais de interaç̧ão(13).

Este tipo de aproximação funciona particularmente bem para interacções direccionais, como é o caso das ligações de hidrogénio. Utilizam este tipo de técnica programas como HSITE(14), LUDI(15) e $\left.\operatorname{HIPPO}^{(9,} 13,16\right)$ (Fig.4).
No entanto, a estrutura de raios $\mathrm{X}$ muitas vezes não está disponível e a maior parte dos programas desenvolvidos podem usar como ponto de partida restrições menos bem definidas como hipóteses farmacofóricas (arranjo tridimensional de grupos funcionais necessários para que uma molécula tenhas um dado efeito biológico). A determinação destas envolve, em geral, a análise conformacional de um conjunto de compostos activos e a identificação de padrões comuns na distribuição espacial de determinados grupos químicos. 

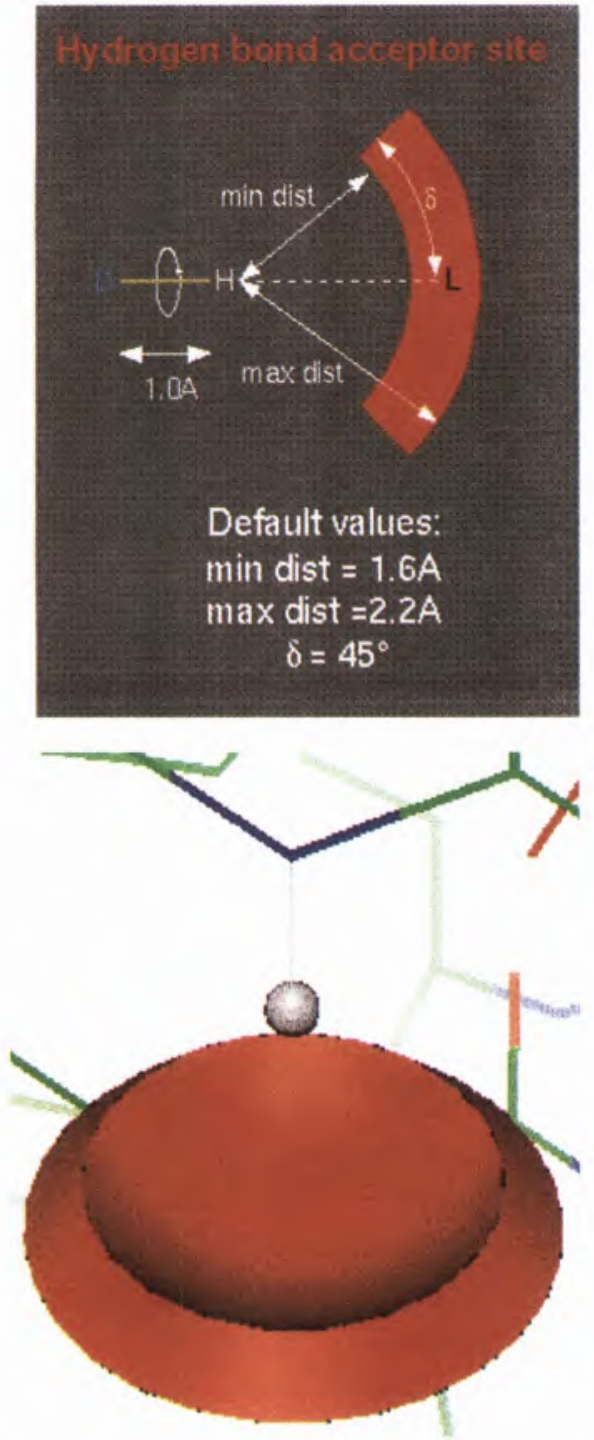

Fig. 2 - Regras para identificação de zonas potenciais de interaç̧ão para ligações de hidrogénio (em que o átomo do ligando é um átomo electronegativo que vai formar a ligação de hidrogénio com um hidrogénio da proteina) e respectiva zona potencial de interacção gerada em 3D. Figura retirada da Ref.9.

Existem também vários programas para a determinação da hipótese farmacofórica, como por exemplo o programa DISCO(17).

\section{Geração de Estruturas}

Este aspecto é fundamental pois é essencialmente a escolha do método para gerar estruturas que vai determinar a qualidade das soluções. Existem, em termos gerais, duas aproximações possíveis:
1) Busca em bases de dados

De certa forma reproduz o método tradicional de desenvolvimento de fármacos, só que os teste iniciais serão feitos pelo computador, portanto serão mais rápidos e mais económicos.

Esta aproximação pode contudo ir mais longe, pois consoante o algoritmo usado será possível reconhecer apenas composto já existentes ou gerar novas moléculas com base em sub-estruturas de compostos conhecidos. No entanto, as soluções apresentadas estão limitadas ao tipo de estruturas na base de dados em que se faz a busca, o que necessariamente limitará a capacidade de propôr estruturas inovadoras. Também o número e tipo de conformações representadas para cada estrutura (em geral limitado, e frequentemente a de mais baixa energia) condicionará os resultados obtidos dado que impossibilitará a identificação de algumas das estruturas existentes na base de dados como potenciais compostos activos. Este é um problema que tem sido bastante estudado estando a ser desenvolvidas técnicas para considerar a flexibilidade molecu$\operatorname{lar}(18,19)$.

Este tipo de aproximação envolve em geral:

a) Identificação da hipótese farmacofórica ou definição do volume do sítio activo e zonas potenciais de interacção;

b) Criação da "pergunta";

c) Busca na base de dados para identificar moléculas que satisfaçam a "pergunta".

Programas representativos desta aproximação são o $\operatorname{DOCK}(11,20)$, o $\operatorname{ALADDIN}(21)$ e o CAVEAT(22).

\section{2) "Design" de Raiz}

Esta técnica permite com base nas características do sítio activo, ou mesmo dentro deste ou de um modelo deste, ir gerando moléculas complementares. Possibilitará assim propôr as soluções mais apropriadas para cada caso e também sugerir moléculas originais e de novas famílias químicas.

Esta é uma técnica ainda muito recente, de facto o primeiro método foi proposto em 1986 e o primeiro programa disponível comercialmente surgiu
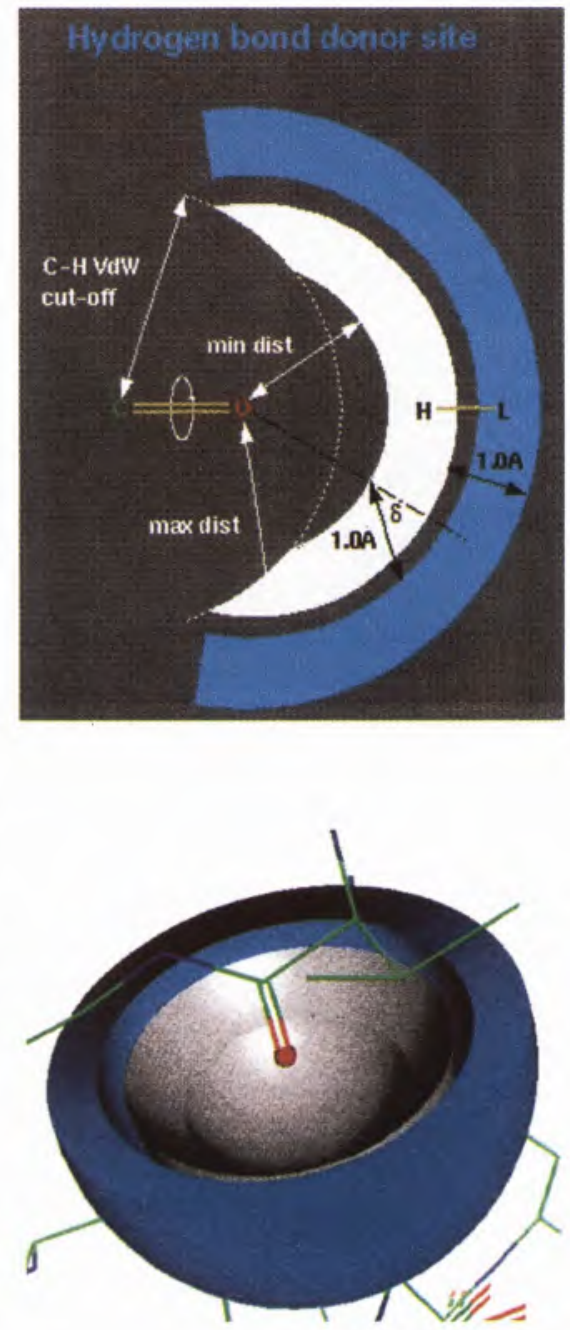

Fig. 3 - Regras para identificação de zonas potenciais de interaç̧ão para ligações de hidrogénio (em que deverá localizar-se um átomo do ligando, que está ligado a um hidrogénio que vai formar uma ligação de hidrogénio com um átomo electronegativo da proteina) e respectiva zona potencial de interacção gerada em 3D. Figura retirada da Ref.9.

em 1992(5). Assim, apesar do seu potencial aparentemente ser enorme, muito trabalho há ainda para fazer. Existem vários grupos, ligados a universidades ou à indústria, a fazer investigação nesta área e são várias as aproximações e técnicas desenvolvidas.

Em geral os programas existentes constroiem as moléculas pela junção de módulos, passo a passo. Dentro desta técnica há ainda diferentes aproximações: 


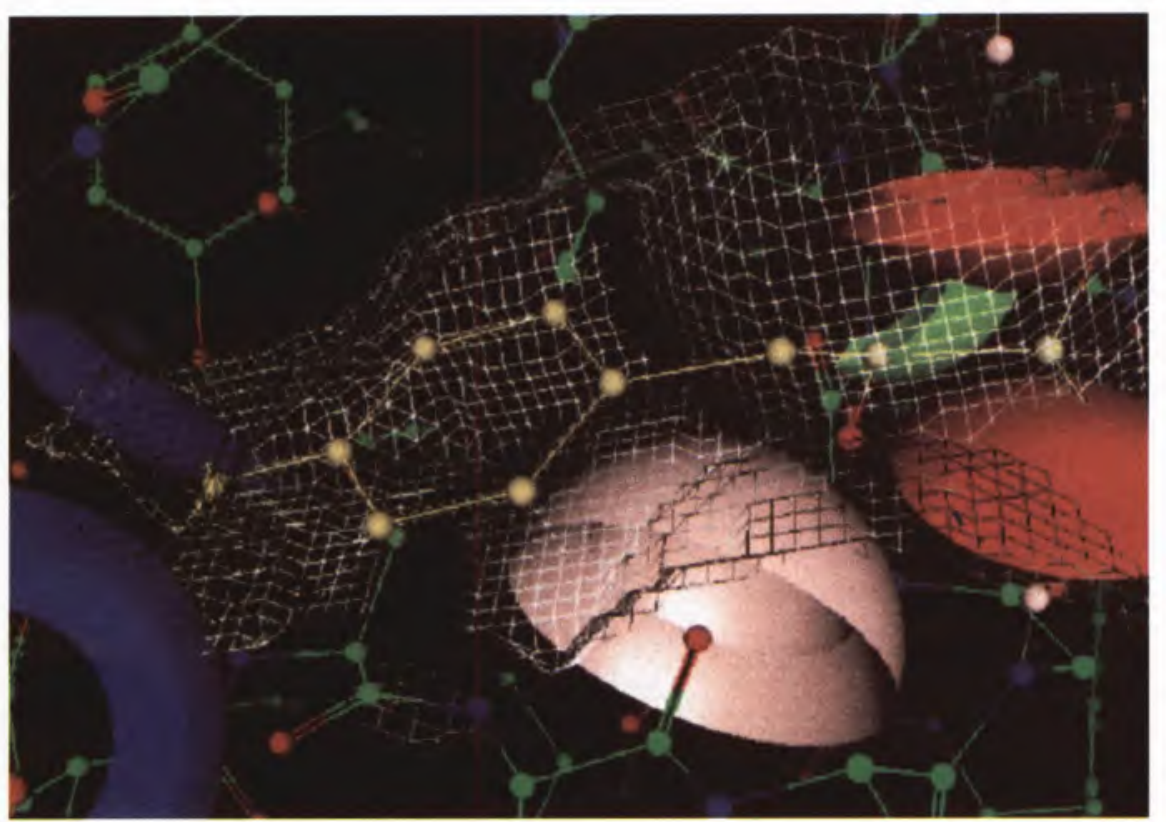

Figura 4 - Ecrã do programa HIPPO, em que a grelha representa a superfície do centro activo e os volumes com diferentes cores representam zonas potenciais de interaç̧ão coloridas consoante as suas características químicas.

Figura retirada da Ref.9.

i) Construção das moléculas átomo a átomo

Esta aproximação tem como inconveniente o facto da geração de estruturas ser muito lenta e de em geral predominarem as estruturas acíclicas, permite no entanto gerar uma diversidade ilimitada de moléculas. São exemplos os programas LEGEND(23) $\mathrm{e}$ GenStar(24). lares

ii) Utilização de módulos molecu-

Esta técnica é em geral mais rápida, permite controlar o tipo de estruturas a gerar (cíclicas ou acíclicas, e mesmo a percentagem de átomos em ciclos) e facilita a geração de estruturas em conformações razoáveis. No entanto, a diversidade de estruturas geradas depende do tipo de módulos na base de dados.

O tipo de módulos moleculares pode ter também características muito diferentes, nomeadamente serem subestruturas com o tipo de átomos e ligações bem definidos(25) ou serem sub-estruturas mais ou menos generalizadas(26). Dado que o tipo de módulos existentes vai limitar a diversidade de moléculas que podem ser geradas, para se conseguir uma boa cobertura em termos estruturais e conformacionais as bases de dados deveriam ser enorme (na base de dados do programa GROW(25), que gera peptídeos pela junção de amino-ácidos, existem 53 conformações para a prolina $\mathrm{e}$ 4987 para a arginina, estando o número de conformações os outros amino-ácidos entre estes valores). A existência de bases de dados muito extensas teria consequências indesejáveis, aumentando muito o tempo de processamento do programas é, portanto, necessário procurar soluções de compromisso.

São exemplos deste tipo de aproximação os programas GROW(25), SPROUT(13,16, 26-28) (Fig. 5 e Fig. 6) e LUDI(15).

A geração de estruturas é uma tarefa computacionalmente muito intensiva e extremamente complexa, apresentando problemas para os quais é difícil encontrar soluções satisfatórias.

O principal problema a ela associado é o da explosão combinatorial de respostas, ou seja muito rapidamente o conjunto de estruturas com que se tem de lidar é enorme, podendo tornar-se inútil dada a dificuldade de o manejar e analisar. Há, assim, necessidade de introduzir na técnica um conjunto de aproximações, sendo algumas das mais comuns na generalidade do programas $(8,15,26)$ :

a) Considerar o receptor rígido;

b) Considerar apenas as interacções com a proteina, não considerando a intervenção de moléculas do solvente nem efeitos de solvatação;

c) Limitar a diversidade de módulos moleculares a usar para gerar as estruturas;

d) Limitar a exploração do espaço conformacional das moléculas geradas:

d) Usar algoritmos de avaliação para reduzir, tanto mais cedo quanto possível, o número de estruturas a considerar.

Os algoritmos desenvolvidos serão, consequentemente, mais rápidos e o conjunto de soluções obtidas limitado e manejável. Tal tem ainda a vantagem de permitir correr o programa interactivamente e assim utilizar a experiência do utilizador. Este aspecto é extremamente importante, dado que por vezes é difícil racionalizar e codificar alguns dos conhecimentos envolvidos no reconhecimento molecular, e a interactividade dos programas permite ao utilizador contribuir com a sua experiência e intuição para a obtenção de soluções. No entanto, a utilização destas aproximações tem o inconveniente de reduzir o rigor e do tipo de soluções obtidas ser estruturalmente mais limitado.

Assim, a qualidade destes programas dependerá, mais do que dos algoritmos de geração de estruturas propriamente ditos, do tipo e qualidade das aproximações implementadas. A qualidade será tanto maior quanto estas forem mais sofisticadas e reflectirem os desenvolvimentos mais recentes nos conhecimentos sobre o reconhecimento molecular, técnicas para considerar a flexibilidade molecular, análise da semelhança entre moléculas, etc.

\section{Avaliação de Estruturas}

As soluções apresentadas ao utilizador não devem ser vistas como solu- 

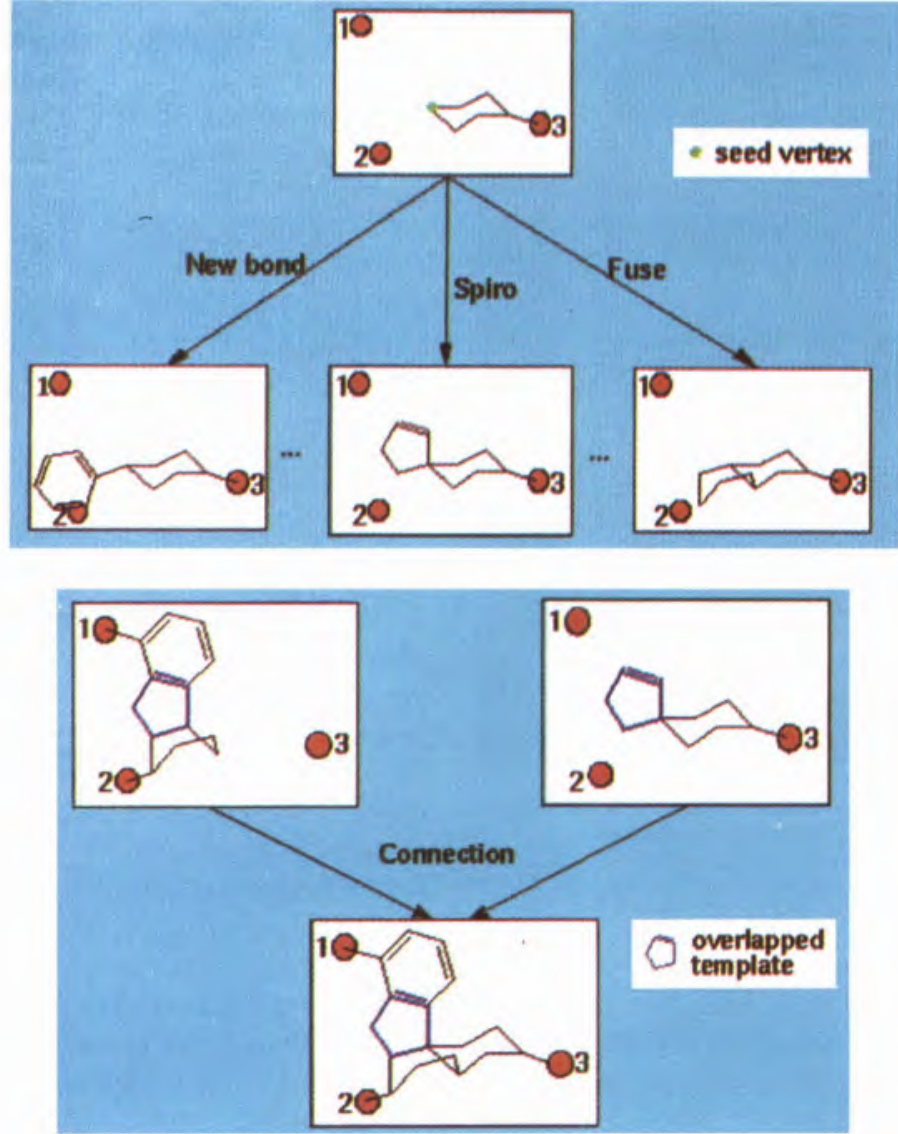

Fig. 5 - Exemplo da geração de estruturas pela junção de módulos moleculares no sistema SPROUT. Figura retirada da Ref. 16.

ções definitivas, mas como sugestões que deverão ser analisadas e optimisadas. No entanto, as soluções propostas devem ser químicamente razoáveis, o que requer uma avaliação das estruturas que vão sendo geradas de forma a produzir e apresentar ao utilizador apenas soluções interessantes.

Nesta avaliação deve considerarse um grande número de propriedades químicas e biológicas como sejam, por exemplo, a energia de interacção entre as proteina e a molécula gerada, a energia da conformação obtida (embora nas situações que envolvem reconhecimento molecular as moléculas nem sempre se encontre na sua conformação de menor energia, a conformação obtida tem que ser razoável), a acessibilidade sintética das soluções propostas e ainda a sua toxicidade potencial ou biodisponibilidade. Tal pode ser levado acabo desenvolvendo módulos que analisem todos estes aspectos, ou desenvolvendo interfaces para comunicação com outros programas existentes que fazem análises nestas áreas $(13,29,30)$.

\section{Organização de Resultados}

Tipicamente, apesar das aproximações utilizadas, estes programas produzem um elevado número de soluções. É assim necessário organizar os resultados e pôr à disposição do utilizador ferramentas para analisar conjuntos grandes de soluções e técnicas para as agrupar e ordenar.

Nesta fase é frequentemente necessário definir uma variedade de critérios, de semelhança molecular ou outros, que podem ser importantes para agrupar ou ordenar as moléculas (semelhança 2D, semelhança 3D, potencial electrostático, dificuldade de síntese...) e haver a possibilidade de poder analisá-las e agrupá-las segundo os diferentes critérios.

\section{Química Combinatorial e "Design" Racional de Fármacos(31-33)}

A química combinatorial é uma técnica que permite que um grande número de moléculas estruturalmente diferentes possam ser sintetizadas de forma extremamente eficiente do ponto de vista de tempo e recursos. Em química combinatorial a síntese de compostos é feita de tal forma que se sintetiza uma vasta gama de análogos usando condições reaccionais semelhantes, seja no mesmo vaso reaccional ou individualmente em paralelo, usando métodos de síntese semi-automáticos. Assim, é possível preparar centenas ou milhares de compostos no tempo que pelos métodos tradicionais se preparavam apenas alguns.

A síntese de compostos usando esta nova técnica teve um impacto enorme na indústria farmacêutica, em particular nos processos de descoberta de novos fármacos. De facto, é um processo que permite muito rapidamente aumentar, em número e variedade estrutural, o conjunto de compostos químicos disponíveis para triagem com o objectivo de identificar compostos activos numa determinada área. Tal permitirá encontrar novos compostos activos em determinadas áreas estruturalmente muito diferentes dos que habitualmente são usados.

A química combinatorial pode também ter um papel a desempenhar na optimização de fármacos protótipo. De facto o conhecimento da estrutura de um dado composto activo pode ser usado para criar um conjunto de análogos directamente relacionados.

Esta aproximação pode dar resultados surpreendentes, mas não envolve um "design" racional, podendo ser particularmente útil quando não existe um conhecimento sobre as bases moleculares da doença. No entanto a combinação das técnicas de "design" racional de moléculas com a química combinatorial pode dar origem a ferra- 
mentas extremamente poderosas para a descoberta de fármacos protótipo e sua optimização. De facto, a química combinatorial aumenta de forma dramática o número de compostos que é possível sintetizar relativamente aos métodos tradicionais, no entanto continua a ser uma tarefa impossível sintetizar e fazer a triagem de milhões de compostos de forma útil para a descoberta eficiente de novos fármacos. Assim, se existe informação estrutural acerca das moléculas envolvidas num dado processo esta pode ser usada para decidir que tipo de moléculas se deverão sintetizar.

Obviamente que os programas que procuram fármacos protótipo analisando bases de dados podem usar indistintamente as bases de dados 3D de compostos existentes ou bases de dados virtuais (conjuntos de compostos que podem ser acessíveis por síntese combinatorial). De facto, dado que é possível ter através da síntese um acesso rápido a estes compostos eles, para estes efeitos, estão na mesma posição que qualquer composto já existente. Dado que não é difícil gerar bases de dados virtuais que poderão conter alguns milhões de moléculas, será razoável esperar que estas possam vir a ter um papel fundamental na descoberta de fármacos protótipo.

Por outro lado, um dos problemas associados às soluções produzidas por grande parte dos programas para "design" racional de raiz é o facto das soluções geradas serem difíceis de sintetizar. Em contraste, a química combinatorial gera grandes conjuntos de moléculas fáceis de sintetizar. Se os algoritmos para geração de estruturas puderem ser direccionados de forma a gerar só moléculas que podem ser acessíveis usando métodos de síntese em paralelo, isto permitirá que as diferentes sugestões possam ser testadas facilmente. Dado que os programas de "design" racional estão ainda no início do seu desenvolvimento é também uma grande vantagem poder, por química combinatorial, sintetizar um elevado número dos compostos sugeridos pelo algoritmo como tendo alguma afinidade

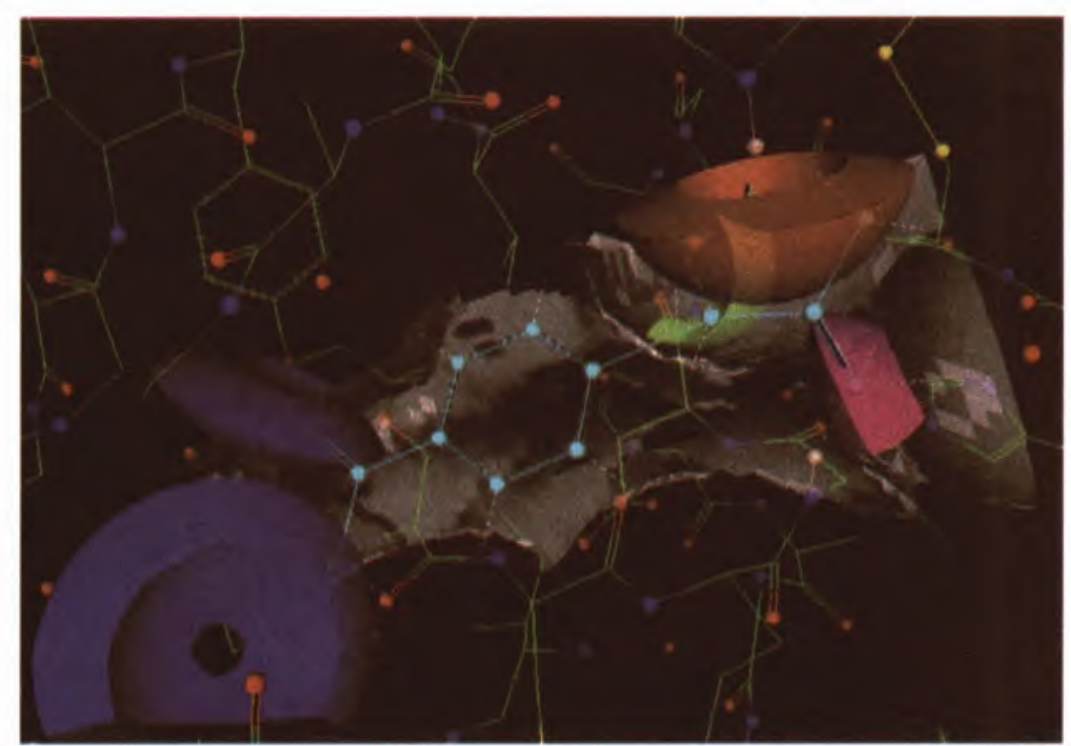

Fig. 6 - Solução gerada pelo programa SPROUT, no contexto do sítio activo, estando representadas as restrições geradas pelo HIPPO.

Figura retirada da Ref. 16.

em vez de se sintetizar apenas as melhores sugestões.

\section{Conclusões}

O "design" racional de fármacos é uma área cujo desenvolvimento se iniciou recentemente estando em grande expansão. Já demonstrou as suas potencialidades, mas um grande caminho há ainda a percorrer particularmente devido à complexidade dos problemas a tratar. Os desenvolvimentos nesta área podem contribuir com um grande peso para a descoberta de forma eficiente e mais económica de novos fármacos, mas além disso podem contribuir também para o desenvolvimento dos conhecimentos sobre reconhecimento molecular. De facto é um método priveligiado para o teste das teorias que vão surgindo sobre o reconhecimento molecular, mas também um bom ponto de partida para o desenvolvimento destas teorias.

É ainda possível associar as técnicas para desenho racional de fármacos a outra área emergente e de grande potencialidade que é a química combinatorial. Tal pode constituir uma verdadeira revolução nos métodos para descoberta de novos fárma- $\cos$, dado que pode dar origem a ferramentas extremamente poderosas para a descoberta de fármacos protótipo e sua optimização.

\footnotetext{
* Departamento de Química, Faculdade de Ciências e Tecnologia, Universidade Nova de Lisboa Quinta da Torre, 2825 Monte da Caparica
}

\section{BIBLIOGRAFIA}

1. A. Korolkovas, I. H. Burckhalter, Química Farmacêutica, Ed. Guanabara, 1988.

2. C. L. Propst, T. I. Perun (Editores), Computer-Aided Drug Design: Methods and Applications, Marcel Dekker, Inc., 1989

3. T. L. Blundell, Nature 384 (Sup, to Issue 6604) (1996) 23.

4. Y. C. Martin, Perspect. Drug Discov, Design 3 (1995) 139.

5. R. A. Lewis, A. R Leach, I. Comput.-Aided Mol, Design 8 (1994) 467.

6. Y. C. Martin, I. Med. Chem. 35 (1992) 2145.

7. A. J. Olson, G. M. Morris, Perspect. Drug Discov. Design 1 (1993) 329 . 
8. "Computer-Aided Drug Design, http://chem.leeds. ac.uk/Project/Teaching/cadd.html.

9. A. P. Johnson, Z. Zsoldos, "Visualisation in the SPROUT molecular design program"http://chem.leeds.ac.uk /ICAMS/people/zsolt/sprout_visual/.

10. M. L. Connolly, J. Mol. Graphics 11 (1993) 139.

11. "DOCK Home Page", http://www.cmpharm. ucsf.edu/kuntz/dock.html.

12. R. C. Wade, K. J. Clark, P. J. Goodford, J. Med. Chem. 36 (1993) 140.

13. V. J. Gillet, G. Myatt, Z. Zsoldos, A. P. Johnson, Perspect. Drug Discov. Design 3 (1995) 34.

14. D. J. Danziger, P. M. Dean, Proc. R. Soc. Lond. B 236 (1989) 101.

15. H.J. Böhm, Perspect. Drug Discov. Design 3 (1995) 21.

16. "SPROUT - a de novo Ligand Design Software", http:/ /chem.leeds.ac.uk/ICAMS/SPROUT.html.
17. M. G. Bures, E. Danaher, J. DeLazzer, Y. C. Martin, J. Chem. Inf. Comput. Sci. 34 (1994), 218.

18. D. E. Clark, G. Jones, P. Willett, J. Chem. Inf. Comput. Sci. 34 (1994) 197.

19. T. Hurst, J. Chem. Inf. Comput. Sci. 34 (1994) 190.

20. J. M. Blaney, J. S. Dixon, Prespect. Drug Discov. Design, 1 (1993) 301.

21. J. H. Van Drie, D. Weininger, Y. C. Martin, J. Comput.Aided Mol. Design 3 (1989), 225.

22. G. Lauri, P. A. Bartlett, J. Comput.-Aided Mol. Design 8 (1994) 51.

23. Y. Nishibata, A. Itai, Tetrahedron 47 (1991) 8985.

24. S. H. Rotstein, M. A. Murcko, J. Comput.-Aided Mol. Design 7 (1993) 23.

25. J. B. Moon, W. J. Howe, Proteins: Struct, Funct., Genet. 11 (1991), 314.
26. P. Mata, V. J. Gillet, A. P Johnson, J. Lampreia, G. J. Myatt, S. Sike, A. L. Stebbings, J. Chem. Inf. Comput. Sci. 35 (1995) 479.

27. V. Gillet, A. P. Johnson, P. Mata, S. Sike, P. Williams, J. Comput.-Aided Mol. Design 7 (1993) 127.

28. V. J. Gillet, W. Newell, P. Mata, G. Myatt, S. Sike, Z. Zsoldos, A. P. Johnson, J. Chem. Inf. Comput. Sci. 34 (1994) 207.

29. "LHASA UK Home Page", http://chem. eeds.ac.uk/LUK/lhasa_uk.html

30. "An Introduction to CAESA", http://chem.leeds.ac.uk/I CAMS/people/jon/caesa/abstract.html

31. N. K. Terrerr, M. Gardner, D. W. Gordon, R. J. Kobylecki, J. Steele, Tetrahedron 51 (1995) 8135.

32. C. Hogan Jr., Nature 384 (Sup. to lssue 6604) (1996) 17

33. E. M. Gordon, M. A. Gallop, D. V. Patel, Acc. Chem. Res. 29 (1996) 144.

\section{Biodinâmica}

\section{Biónica Aplicada Lda.}

RUA DA GUINÉ, $2-2^{\circ} \mathrm{E}$

1100 LISBOA-PORTUGAL

TEL. 8150760 - FAX 8150770

\section{INSTRUMENTAÇÃO}

HI-TECH SCIENTIFIC - Stopped Flow e instrumentação para estudos de cinética de reacções rápidas.

PHOTON TECHNOLOGY INTERNATIONAL (PTI) - Fontes de Radiação, Fluorimetros (estado estacionário e de tempos de vida), Lasers de Azoto com ou sem laser de corantes, Fluorescência de Rácio, software.

IBH - Tempos de vida, Lâmpadas pulsadas, Detecção ultra rápida (fotomultiplicadores e instrumentação), software.

OLIS - Espectrofotómetros clássicos modernizados. Monocromadores de Scanning Rápido (até 1000 scans/sec).

CANBERRA INDUSTRIES - Instrumentação nuclear, detectores de estado sólido, etc.

BROOKHAVEN INSTRUMENTS - Analisadores de tamanho de partículas por dispersão de luz, centrifugação e electrocinética.

KINETIC SYSTEMS - Mesas e "breadboards" para óptica.

GENTEC - Medidores de energia para lasers.

LASER SHIELD - Óculos de protecção para radiação laser (Nd-Yag, $\left.\mathrm{CO}_{2}, \mathrm{He}-\mathrm{Ne}\right)$, espectro largo e UV.

CORION - Gama completa de filtros ópticos.

STRAWBERRY TREE COMPUTERS - Placas e software para aquisição de dados.

HELLMA - Células (cuvettes) em vidro e quartzo.

Desenvolvimento e construção de instrumentação.

Exponha-nos as suas necessidades 